\title{
Tsunami Field Survey of the 1992 Nicaragua Earthquake
}

PAGES 145, 156-157

\section{Kenji Satake, Joanne Bourgeois, Kuniaki Abe, Katsuyuki Abe, Yoshinobu Tsuji, Fumihiko Imamura, Yoshihisa Iio, Hiroshi Katao, Evelyn Noguera, and Francisco Estrada}

An earthquake with surface magnitude $\left(M_{s}\right) 7.0$ occurred $100 \mathrm{~km}$ off the Nicaraguan coast on September 2, 1992 (GMT). Despite its moderate size, this earthquake generated a sizable tsunami, which caused extensive damage along the coast of Nicaragua. In late September, about 170 people, mostly children, were listed dead or missing; 500 were listed injured; and over 13,000 were listed homeless, with more than 1500 homes destroyed. Damage was the most significant since the 1983 Japan Sea earthquake tsunami, which killed 100 people in Japan. The Flores (Indonesia) earthquake and tsunami of December 12, 1992, were more destructive than the Nicaragua or Japan Sea events.

Within a few days of the Nicaragua earthquake, we made a preliminary analysis of available seismic and tsunami data. Our studies indicated that this earthquake had features typical of a "tsunami earthquake," which generates an unusually large tsunami relative to earthquake magnitude [Kanamori, 1972]. It is different than a "tsunamigenic earthquake," which is any earthquake that generates a tsunami. To document this unusual tsunami, we surveyed the Nicaraguan coast in late September.

\section{Semi-Real-Time Analysis of Seismic and Tsunami Data}

Off the Pacific coast of Nicaragua, the Cocos plate is being subducted beneath the

Kenji Satake, Department of Geological Sciences, University of Michigan, Ann Arbor, MI 48109; Joanne Bourgeois, Department of Geological Sciences, University of Washington, Seattle, WA 98195; Kuniaki Abe, Niigata Junior College, Nippon Dental University, Japan; Katsuyuki Abe and Yoshinobu Tsuji, Earthquake Research Institute, University of Tokyo, Japan; Fumihiko Imamura, Disaster Control Research Center, Tohoku University, Japan; Yoshihisa lio and Hiroshi Katao, Disaster Prevention Research Institute, Kyoto University, Japan; Evelyn Noguera, Asociacion National de Geologos y Profesionales Afines, Nicaragua; and Francisco Estrada, National Institute of Environment and Natural Resource, Nicaragua
Caribbean plate (Figure 1) at a convergence rate of about $8 \mathrm{~cm} / \mathrm{yr}$. Based on data from a seismic network of sixteen stations installed by the U.S. Geological Survey in Nicaragua after the 1972 Managua (intraplate) earthquake, Harlow et al. [1981] characterized the seismicity of the subduction zone and pointed out a seismic gap; the 1992 earthquake occurred in this gap. This seismic network has fallen into disrepair since the Nicaraguan Civil War, and only very limited local data are available for the event. However, within a few hours after the earthquake, seismograms of the event from ten stations in the United States, Europe, and Japan were stored at the Incorporated Research Institutions for Seismology's Data Management Center and were available by computer network. The aftershock epicenters located by the USGS National Earthquake Information Service were also available by computer network or telephone. Some digital tide-gauge data were available through the National Oceanic and Atmospheric Administration's Pacific Tsunami Warning Center and National Ocean Survey. Within a few days of the earthquake, we were able to make a preliminary analysis of these data.

The focal mechanism of the 1992 event, determined from long-period surface waves (Figure 1), exhibits a thrust-fault within a plane dipping shallowly toward the northeast, consistent with subduction of the Cocos plate. Aftershocks occurred in an area about $200 \mathrm{~km}$ along-strike by $100-\mathrm{km}$ downdip of the trench (Figure 1); similar to aftershock areas of other tsunami earthquakes, this area is adjacent to the trench axis.

Preliminary waveform analysis of both long-period surface and body waves indicates a duration of at least $100 \mathrm{~s}$, much longer than is typical of an earthquake of $M_{s}=7$. This is evident in Figure 2, which shows a comparison of the moment release rate from the sources of the Nicaragua earthquake and the $\mathrm{M}_{\mathrm{s}}=7.1$ Cape Mendocino (Petrolia) earthquake of April 25, 1992. The seismic moment, which is a time integral of the moment rate, is much larger for the Nicaragua event, about $4 \times 10^{20} \mathrm{Nm}$, or a moment magnitude $M_{w}=7.7$; for the Cape Mendocino event, it is about $5 \times 10^{19} \mathrm{Nm}$, or $\mathrm{M}_{\mathrm{w}}=7.1$.

The tsunami generated by the 1992 Nicaraguan earthquake was recorded by tide gauges in the Pacific Ocean, with a peak-topeak amplitude of about $1 \mathrm{~m}$ at Easter and $90^{\circ} \mathrm{W} \quad 85^{\circ} \mathrm{W}$

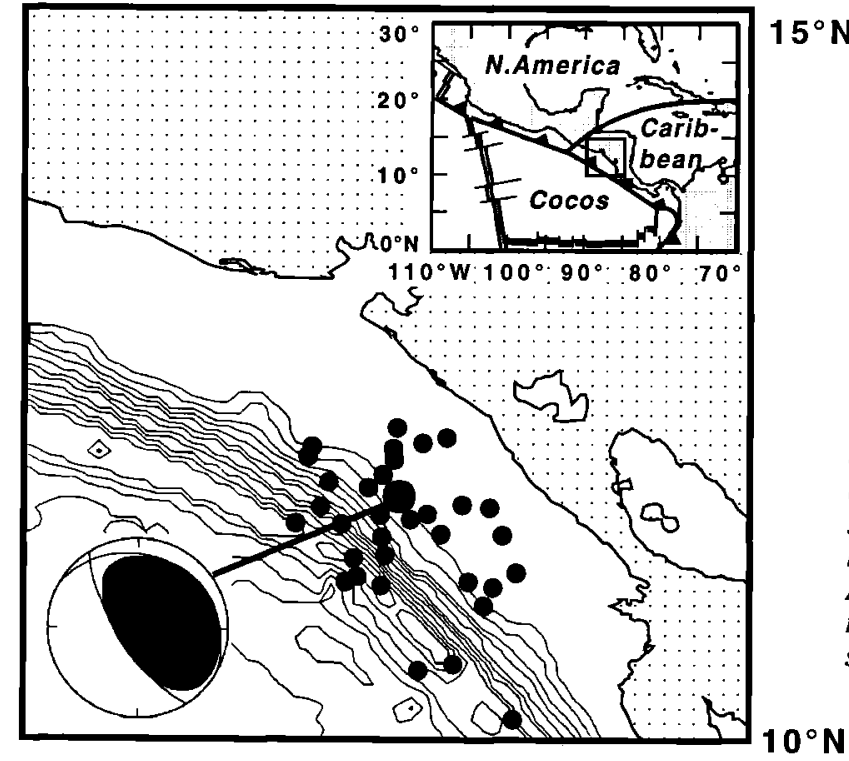

Fig. 1. The map of the Pacific coast of Nicaragua with locations of mainshock (larger solid circle) and aftershocks that occurred within I day of the mainshock (smaller solid circles). The focal mechanism of the mainshock is also shown. The inset shows the tectonic framework of central America and the area for the main map ( $a$ square). 
Galapagos islands and about $10 \mathrm{~cm}$ at Hilo, Hawaii, and Kesen'numa, Japan. From these far-field tsunami amplitudes, we calculated a tsunami magnitude [Abe, 1979], $\mathrm{M}_{\mathrm{t}}=8.0$ for this event.

\section{Field Survey of Tsunami Run-Up Heights}

Our field team comprised six scientists and engineers from Japan and two from the United States, aided by local Nicaraguan scientists and engineers; their areas of expertise included seismology, oceanography, coastal engineering, and geology. From this group, three teams were deployed along the Pacific coast each day for about a week in late September. Other participants in posttsunami surveys of the Nicaraguan coast are listed at the end of this article. Our survey included interviewing local residents, collecting evidence of tsunami effects, and mea suring run-up heights and beach slopes. Our team made more than sixty measurements. At El Transito we conducted a more extensive survey of the inundation area. We used interviews, which varied significantly in reliability, to estimate earthquake shaking, tsunami arrival time, and run-up or inundation levels. Interestingly, only about half the people interviewed felt the earthquake, despite the short epicentral distance (about $100 \mathrm{~km}$ ). Some interviewees only reported noise and shaking immediately before the tsunami arrival. The earthquake was described as weak and soft, probably corresponding to III on the Modified Mercalli Scale. Reports of tsunami arrival time were variable, but some accurate times, around 8:00 P.M., were given by people who were watching television. In general, healthy adults were able to outrun the incoming tsunami; virtually all casualties were children or adults who were sleeping or physically impaired. Most eyewitnesses reported only one significant wave. The tsunami arrived within an hour after high tide, so run-up levels and damage were nearly the maximum possible.

A variety of indicators were used to measure tsunami run-up. We considered physical indicators corroborated by eyewitnesses

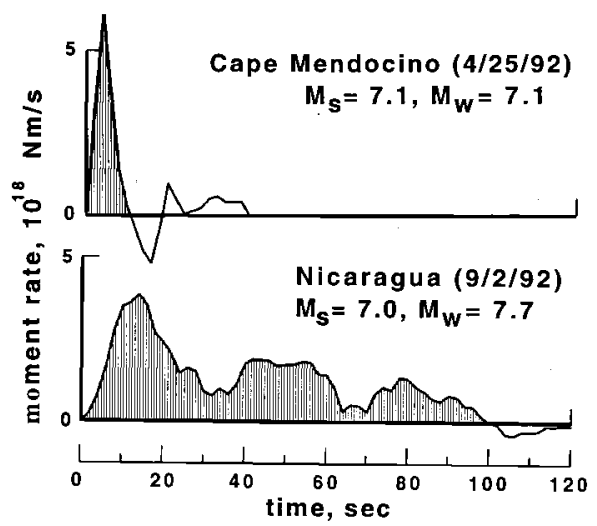

Fig. 2. The source time functions of the Cape Mendocino earthquake (April 25, 1992) and the Nicaragua earthquake (September 2, 1992). After Ruff et al. (1992/.

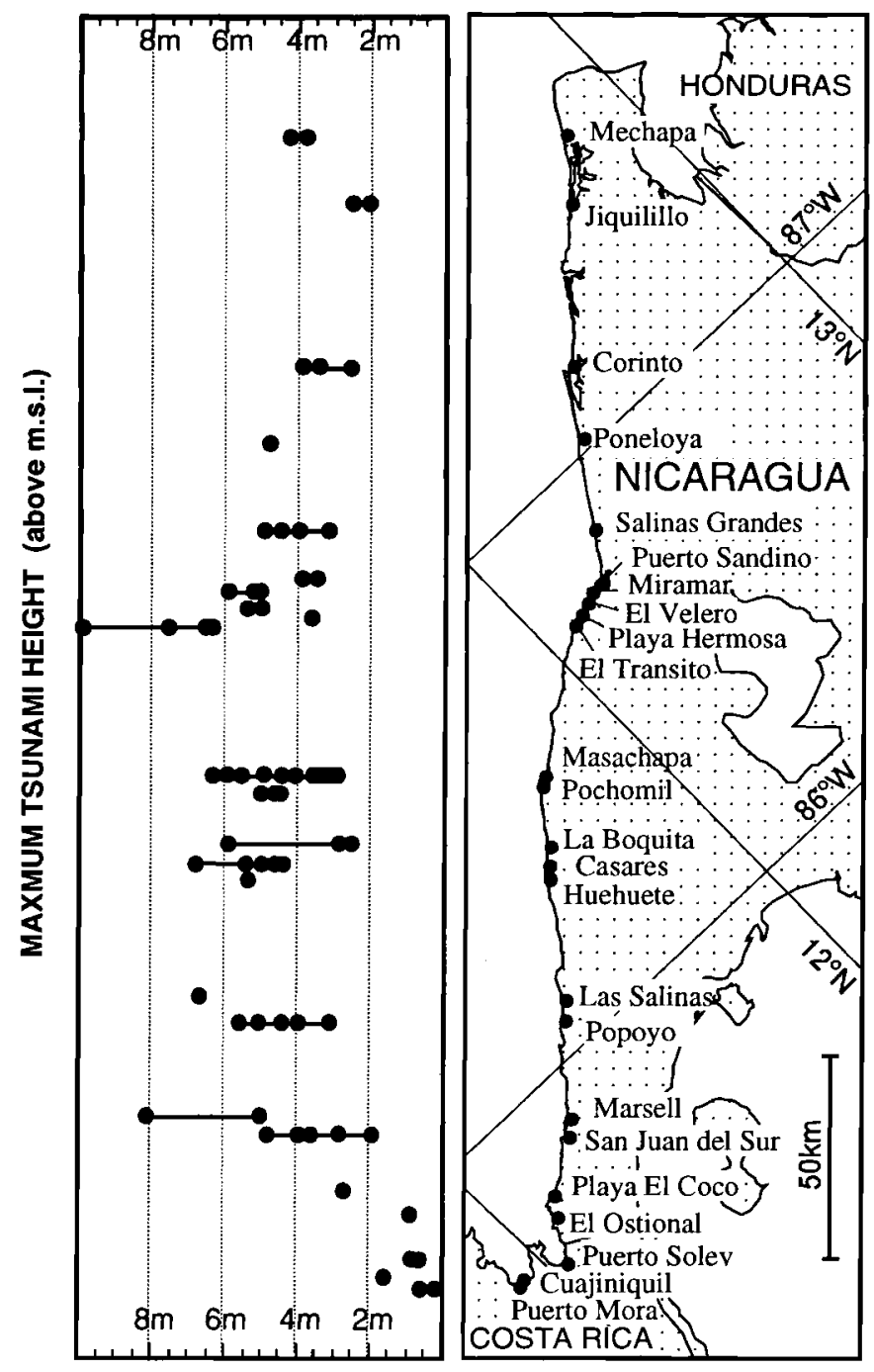

Fig. 3. The tsunami run-up heights along the Pacific coast of Nicaragua. The solid circles show the tsunami run-up heights above the mean sea level, and the bars show the data range for multiple measurements.

most reliable, followed by distinct physical indicators or consistent eyewitness accounts; some eyewitness accounts and physical indicators were equivocal. Horizontal water marks ("bathtub rings") on walls most clearly indicated water level; horizontal boundaries between vegetation killed or damaged by saltwater and surviving vegetation were also considered reliable. Additional data included levels of seaweed or debris caught in screens or other structures and amounts of bark stripped from trees. We also measured the elevation of damage to buildings and heights of gashes where transported debris hit trees. However, we considered this measurement less reliable because the gashes may be due to secondary effects such as transport of floating debris by the tsunami. Sand eroded from the beach was transported and deposited over most of the inundation area of the tsunami, and natural and man-made clasts up to boulder size were commonly transported for tens of meters. Landward limit of debris or sediment deposition was measured in some locations.

We measured run-up heights relative to local sea level at the time of measurement and then corrected to heights above mean sea level (the standard for comparison) from tide tables (Figure 3 ). Tsunami run-up heights vary locally, mostly in the range of 2-6 $\mathrm{m}$. The highest run-up datum, nearly 10 $\mathrm{m}$, is from El Transito, where detailed surveying indicated large local variation possibly due to reflection off local hillsides. Similar local variation was found around San Juan del Sur, in an area characterized by many small bays. Some of these local variations may be due to near-shore bottom topography.

Size of tsunamis has been described by the Imamura-lida scale, $m$, roughly equal to $\log _{2} H$ where $H$ is maximum local tsunami run-up height. Therefore, for the Nicaragua tsunami, $m$ is approximately 3 , and according to the empirical relationship between $m$ and earthquake size, the observed run-up heights are typical of earthquake magnitude of about 8 . Thus, the field survey result also shows that the 1992 Nicaragua earthquake produced an unusually large tsunami.

\section{Future Studies}

Data collected from this event will be valuable for future studies on various aspects of tsunamis. Generation mechanism of "tsunami earthquakes" is still not wellknown [e.g., Pelayo and Wiens, 1992], and few modeling studies have been done. Using 
results from this survey, we can test possible mechanisms by comparing numerical computations from various source models with field observations [e.g., Satake, 1989]. An important goal of such studies is to allow prediction of these unusual tsunamis in time to warn coastal communities. Also, nearshore behavior of tsunamis will be studied both numerically and experimentally, with Nicaragua as a test case, and tsunami deposits from this event may provide an important calibration for geologists who study paleo-tsunami deposits and try to estimate paleoseismology. In addition, the collected data will help planners to develop guidelines for tsunami hazard mitigation both in Nicaragua and along other coastlines susceptible to tsunamis.

\section{Acknowledgments}

We would like to thank the staff of Insituto Nicaraguense de Estudios Territoriales (INETER) for their generous hospitality and support of our efforts. Harry Yeh of the University of Washington and Costas Synolakis of the University of Southern California helped collect run-up data from El Popoyo and northern Costa Rica. The aerial survey by Frank Gonzalez of PMEL, NOAA was useful for planning field checks. Other U.S. participants in post-tsunami surveys of the Nicaraguan coast include Mehmet Celebi and David Harlow, USGS, Menlo Park, Calif.; Arturo Aburto, University of Nevada; and Jane Preuss, Urban Regional Research, Seattle.
Wash. Recently, another team, consisting of Tad Murty, Institute of Ocean Sciences, Canada; Antonio Baptista, Oregon Graduate Institute of Science and Technology; and George Priest, Oregon Department of Geology and Mineral Industries, visited the Nicaraguan coast and made a complementary survey of tsunami run-up heights. K. Satake's research is supported by NSF grant

EAR-9117800. J. Bourgeois' travel was supported by NSF. The Japanese team was supported by Ministry of Education, Science and Culture, Japan.

\section{References}

Abe, K., Size of great earthquakes of 1873-1974 inferred from tsunami data, J. Geophys. Res., 84, 1561,1979

Harlow, D. H., R. A. White, I. L. Cifuentes, and A. Aburto, Quiet zone within a seismic gap near western Nicaragua: Possible location of a future large earthquake, Science, 213, 648, 1981

Kanamori, H., Mechanism of tsunami earthquakes, Phys. Earth Planet. Inter., 6, 346, 1972.

Pelayo, A. M., and D. A. Wiens, Tsunami earthquakes: Slow thrust-faulting events in the accretionary wedge, J. Geophys. Res., 97, 15321, 1992.

Ruff, L. J., K. Satake, Y. Tanioka, and J. M. Johnson, Preliminary analysis of the 1992 Nicaragua earthquake (abstract), Eos Trans. AGU, 73 , $353,1992$.

Satake, K., Inversion of tsunami waveforms for the estimation of heterogeneous fault motion of large submarine earthquakes: The 1968 Tokachioki and the 1983 Japan Sea earthquakes, $J$. Geophys. Res., 94, 5627, 1989.

\section{Earthquake Prediction Lessons from Parkfield Experiment \\ PAGES 145, 153-155}

\section{Andrew J. Michael and John Langbein}

In 1985, the National Earthquake Prediction Evaluation Council (NEPEC), and later its California counterpart (CEPEC), approved an earthquake prediction for the first time. This was the Bakun and Lindh [1985] forecast, with $95 \%$ confidence, that an $\mathrm{M}=5.5$ to 6 earthquake would rupture along the San Andreas fault near the town of Parkfield before 1993. This forecast was an important factor in selecting the Parkfield area for a major geophysical and geological monitoring study. The experiments installed there are aimed at producing a better understanding of the earthquake generation process and earthquake effects, gaining experience with real-time monitoring of a variety of geophysical data, and, if possible, making a shortterm prediction of the future earthquake. Twenty-eight different observational networks now exist in the Parkfield area. The forecast also generated interest that led researchers

\footnotetext{
U.S. Geological Survey, MS/977, 345 Middlefield
} Road, Menlo Park, CA 94025 to reexamine past Parkfield earthquakes with current knowledge and to develop new models of the earthquake cycle.

As 1993 approached, the USGS convened a meeting of the investigators who have worked on Parkfield to summarize what has been learned and how the experiment should be modified to better achieve its goals. This review took place at the University of California, Santa Cruz, which cosponsored the June 28-30, 1992, meeting. Despite the occurrence of the M7.5 Landers earthquake only 12 hours before the meeting began, fifty-two invited participants from the USGS, various universities, and California attended.

The meeting was broken into four broad subject areas: long-term forecast, physical modeling of the Parkfield region and the earthquake generation process, the monitoring experiments, and post-earthquake effects Topic discussions were led by Terry Tullis of Brown University, Mark Matthews of the Massachusetts Institute of Technology, Evelyn
Roeloffs of the USGS, and John Schneider of the Electrical Power Research Institute, respectively. A summary discussion was moderated by Andrew Michael of the USGS.

\section{Forecast}

Much of the attention given to Parkfield centers on the prediction that its next mainshock was likely to occur before 1993. Matthews proposed that a strictly statistical analysis of the sequence of past Parkfield earthquakes from 1857 to 1966 yields a T distribution of the time of the next earthquake centered on 1982 with a $95 \%$ confidence level of \pm 18.6 years. While this confidence interval is as large as the average inter-event interval, it may well be reasonable: of the five previous inter-event intervals, two deviate by 10 years from the average and in a set of five samples, there is no reason to expect that we have seen the tails of the distribution

Bakun and Lindh got a 95\% confidence interval of \pm 5 years centered on 1988 by assuming that the 1934 earthquake was triggered early by the 1934 foreshock sequence With a physical model to explain why the 1934 could be as large as the other events, they argued that this allows them to ignore the 1934 event when computing the center of the distribution but include it when computing the spread of the distribution.

Another choice that affects computation of probabilities is how the knowledge that the next Parkfield mainshock has yet to occur is included. Thus, the next inter-event interval will be longer than the average. Such a model was presented by Dave Jackson, University of California, Los Angeles. This model concludes that the current probability of the mainshock occurring is $6.4 \%$ per year and declining. On physical grounds, such a model seems to ignore the accumulating strain on the fault due to continued plate motions. This should increase the probability of the earthquake with time instead of having it decrease, particularly if each Parkfield earthquake does rupture the same part of the fault. Such repeated rupture of the same fault segment was questioned by Paul Segall, USGS and Stanford University, who showed geodetic information indicating that the 1934 and 1966 events may have released moment from different parts of the fault. If the mainshocks differ in their spatial extent, then simple models that store strain and release it from the same place each time may lead to the wrong probabilities. Uncertainty in the geodetic results hinges on the possibility that the differences are due to postseismic slip and not the mainshock.

Another problem is how to treat the 1857 earthquakes. While the 1857 Parkfield earthquake-a possible foreshock to the 1857 Fort Tejon earthquake-is poorly understood, it is clear that the Fort Tejon earthquake significantly affected this region. If it removed all stored strain from the San Andreas fault at Parkfield, then it can be treated as a fixed point from which all subsequent activity starts. If, however, one treats the 1857 Parkfield quake the same as any other 